\title{
ANALISIS PERBANDINGAN PERFORMA POINT-TO-POINT TUNNELING PROTOCOL DAN ETHERNET OVER INTERNET PROTOCOL DALAM MEMBENTUK VPN
}

\author{
Robby Triadi Susanto ${ }^{(1)}$ \\ robbytriadi@gmail.com
}

\author{
Gani Indriyanta ${ }^{(2)}$ \\ ganind@ukdw.ac.id
}

\author{
R. Gunawan Santosa ${ }^{(3)}$ \\ gunawan@ukdw.ac.id
}

\begin{abstract}
Virtual Private Network (VPN) is a technology implemented as a solution to connect head and branch offices through a network. VPN enables all offices connected to be treated as a single broadcast domain or a single network, providing a private connection. $V P N$ can be implemented over several protocols: Point-To-Point Tunneling Protocol (PPTP) and Ethernet over Internet Protocol (EoIP).

This research conducted through implementation of both protocols on a site-to site $V P N$ and measuring each protocol's performance using throughput, packet loss and delay parameters obtained from real topology.

Overall result shows that EoIP performs better than PPTP. Within six days of observation, obtained data shows that EoIP has better throughput and less delay than PPTP, while PPTP has a smaller rate of packet loss than EoIP.
\end{abstract}

Kata kunci: Virtual Private Network (VPN), Point-to-point Tunneling Procol (PPTP), Ethernet over Internet Protocol (EoIP)

\section{Pendahuluan}

Saat ini, Internet telah menjadi kebutuhan yang pokok bagi organisasi.Berbagai teknologi yang dikembangkan pada jaringan Internet sudah mulai diimplementasikan pada organisasi. Virtual Private Network (VPN) merupakan salah satu teknologi yang diimplementasikan sebagai solusi atas kebutuhan untuk menghubungkan kantor pusat dan kantor cabang.VPN dapat menghubungkan kantor cabang dan kantor pusat melalui jaringan publik (misalnya Internet) seolah-olah menjadi sebuah jaringan privat dengan membuat sebuah "terowongan" ("tunnel") tanpa membuat jalur khusus secara fisik, sehingga komunikasi antar kantor dalam organisasi dapat dilakukan secara aman.VPN memungkinkan membentuk kantor pusat dan kantor cabang menjadi satu broadcast domain atau satu network yang sama walaupun terpisah oleh jaringan publik, sehingga kantor pusat dan kantor cabang akan dapat berkomunkasi secara privat. Protokol yang digunakan untuk membentuk sebuah "terowongan" (tunneling protocol) ini bermacam-macam, diantaranya: Point-To-Point Tunneling Protocol (PPTP), dan Ethernet over Internet Protocol (EoIP) yang merupakan tunneling pada Layer 2.

\section{Teori Pendukung}

\subsection{Virtual Private Network (VPN)}

Virtual Private Network (VPN) adalah tiruan dari sebuah fasilitas Wide Area Network (WAN) privat menggunakan fasilitas IP (termasuk Internet publik, atau backbone

\footnotetext{
${ }^{I}$ Alumni Teknik Informatika, Fakultas Teknologi Informasi, Universitas Kristen Duta Wacana

${ }^{2}$ Dosen Teknik Informatika, Fakultas Teknologi Informasi, Universitas Kristen Duta Wacana

${ }^{3}$ DosenTeknik Informatika, Fakultas Teknologi Informasi, Universitas Kristen Duta Wacana
} 
IP privat). (Gleeson, 2000). VPN menyediakan komunikasi privat antar end user, seperti remote office dan telecommuters. (Luo, 2005). Banyak organisasi menggunakan VPN untuk menghubungkan kantor, home office, rekan bisnis dan masih banyak lagi. Selain karena murah dan mudah digunakan, VPN juga digunakan karena mengutamakan keamanan. "VPN merupakan sebuah sarana untuk mengamankan dan memprivatkan pengiriman data melalui sebuah insfrastruktur jaringan yang tidak aman dan dapat digunakan bersama (shared)" (Vachon, 2008, halaman 402). VPN dikatakan aman karena semua data yang ditransimisikan melalui sebuah terowongan (tunnel) selalu dienkripsi menggunakan algortima-algoritma tertentu, bergantung pada protokol yang digunakan.

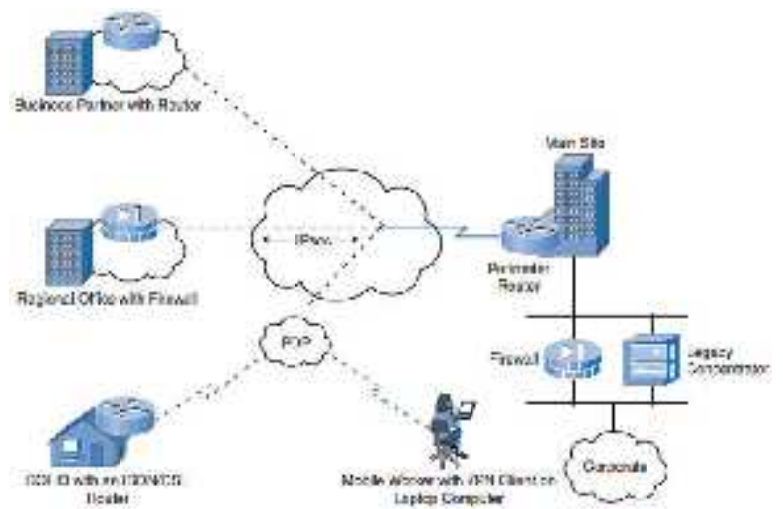

Gambar 1.Komponen dan Teknologi VPN

(Dikutip dari: Vachon, B dan Graziani, R. (2008). Accessing the WAN-CCNA Exploration Companion Guide. Indianapolis: Cisco Press, halaman 402.)

\subsection{VPN Tunneling}

Tunneling merupakan dasar atau inti dari teknologi VPN. "Tunneling adalah teknik enkapsulasi seluruh paket data ke dalam format protokol lain." (Gupta, 2003)."Tunneling mengijinkan penggunaan jaringan publik seperti Internet untuk membawa data kepada pengguna seolah-olah pengguna memiliki akses ke sebuah jaringan privat."(Vachon, 2008, halaman 409).Tunneling bekerja pada Layer 2 Model OSI Layer.

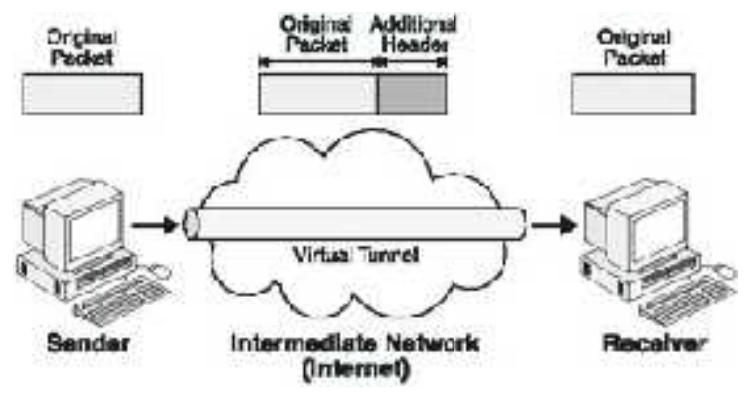

Gambar 2.Proses Tunneling

Dikutip dari: Gupta, M. (2003). Building a Virtual Private Network, Part II Chapter 4. Ohio: Premier Press.

Gambar 2. menjelaskan bagaimana proses pengenkapsulasian paket data ke dalam format lain. Paket yang dienkapsulasi tidak dirubah, tetapi ditambahkan sebuah header yang pada saat paket ditransmisikan ke dalam jaringan.Hal ini membuat paket yang asli tidak berubah nilainya ketika dikirim dan diterima. 


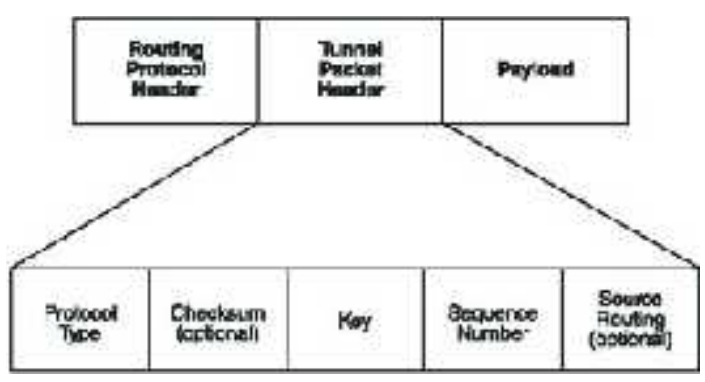

Gambar 3.Format Paket Tunneling

(Dikutip dari: Gupta, M. (2003). Building a Virtual Private Network, Part II Chapter 4.

Ohio: Premier Press.)

Gambar di atas adalah format paket yang telah dienkripsi dan ditransmisikan melalui tunnel.Pengenkripsian dilakukan dengan menambahkan sebuah header baru pada paket yang akan ditransmisikan melalui tunnel, yaitu tunnel packet header. Berikut ini adalah penjelasan dari format paket tunneling seperti pada Gambar 2.7. (Gupta, 2003):

- Routing Protocol Header, berisi alamat IP asal tujuan. Header ini adalah header standar yang ada pada setiap paket karena transmisi paket melalui Internet pada umumnya berbasis IP.

- Tunnel Packet Header, header ini berisi lima field, yaitu:

- Protocol type, berisi tipe protokol paket data yang asli.

- Checksum, berisi checksum yang digunakan untuk mengetahui paket yang tidak sampai atau korup selama paket dikirimkan. Informasi ini tidak harus ada.

- Key, berisi informasi yang digunakan untuk mengidentifikasi atau mengotentikasi sumber data yang aktual (inisiator).

- Sequence number, berisi nomor urut paket yang ditransmisikan.

- Source routing, berisi informasi routing tambahan. Informasi ini tidak harus ada.

- Payload, berisi paket asli yang dikirimkan oleh alamat asal. Selain itu, payload juga berisi header asli.

Dalam melakukan enkapsulasi, tunneling menggunakan tiga kelas protokol seperti yang ditunjukkan pada Gambar 4., yaitu:

\section{- Carrier Protocol}

Protokol ini berisi tentang informasi teknologi pembawa seperti: Frame Relay, ATM, dan MPLS. "Protokol ini digunakan untuk mengarahkan tunneled packet ke tujuan yang dimaksud melalui jaringan (internetwork)." (Gupta, 2003).Dalam penggunaannya di Internet, carrier protocol yang digunakan adalah IP. Namun, dibeberapa jaringan jaringan lain seperti intranet, protokol routing dapat juga berfungsi sebagai protokol pembawa.

\section{- Encapsulating Protocol}

Protokol ini adalah protokol pembungkus data yang asli."Protokol ini juga bertanggung jawab untuk membuat, merawat (maintenance) dan menutup (terminate) terowongan" (Gupta, 2003). Contoh protokol ini antara lain: Generic Encapsulation Routing (GRE), IPSec, L2F, PPTP dan L2TP.

\section{- Passenger Protocol}

Protokol ini berisi tentang data asli yang dibawa, seperti: IPX, AppleTalk, IPv4, IPv6, PPP dan SLIP (Serial Line Internet Protocol)). PPP dan SLIP adalah passenger protocol yang sering digunakan. 


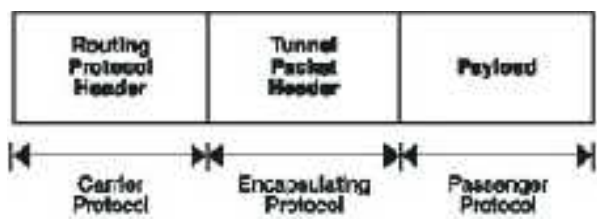

Gambar 4.Pemetaan Paket Tunneling

(Dikutip dari: Gupta, M. (2003). Building a Virtual Private Network, Part II Chapter 4.

Ohio: Premier Press.)

\subsection{Point-to-Point Tunneling Protocol (PPTP)}

Definisi PPTP menurut Microsoft (diakses dari http://technet.microsoft.com/enus/library/cc768084.aspxpada tanggal 5 April 2012) yaitu: "Point-To-Point Tunneling Protocol adalah protokol jaringan yang memungkinkan transfer data yang aman dari sebuah remote client ke sebuah enterprise server yang privat dengan membuat sebuah virtual private network(VPN) melalui jaringan data berbasis TCP/IP." Point-To-Point Tunneling Protocol (PPTP) dikembangkan oleh PPTP Consortium(Microsoft Corporation, Ascend Communications, 3COM, US Robotics, dan ECI Telematics).PPTP adalah sebuah protokol jaringan yang mengenkapsulasi paket PPP kedalam IP datagram untuk transmisi melalui Internet atau jaringan publik.

Menurut Gupta (2003), dua fenomena yang memainkan peran utama dalam suksesnya PPTP dalam hubungan jarak jauh yang aman adalah:

- Penggunaan PSTN (Public Switched Telephone Networks)

Pengimplementasian PPTP yang dapat dilakukan PSTN membuat proses penyebaran PPTP menjadi sangat sederhana dan membutuhkan biaya yang relatif kecil. Hal ini membuat koneksi perusahaan-perusahaan besar yang berbasis leased line dan dedicated communication server dapat benar-benar dihilangkan.

\section{- Dukungan untuk protokol Non-IP}

Walaupun fungsi PPTP yang sebenarnya untuk digunakan pada jaringan berbasis IP, namun PPTP dapat digunakan pada protokol yang lain seperti TCP/IP, IPX, NetBEUI, dan NetBIOS.

"PPP memainkan peranan utama dalam transaksi berbasis PPTP...PPTP adalah perpanjangan logika dari PPP sehingga PPTP tidak merubah inti dari teknologi PPP."(Gupta, 2003). Gupta (2003) juga menjelaskan fungsi PPP dalam transaksi berbasis PPTP seperti pada Gambar 5., yaitu:

- Mendirikan dan mengakhiri koneksi fisik komunikasi antara dua ujung.

- Mengotentikasi client PPTP.

- Mengenkripsi datagram pada protokol IPX, NetBEUI, NetBIOS, dan TCP/IP untuk membuat datagram PPP dan mengamankan pertukaran data.

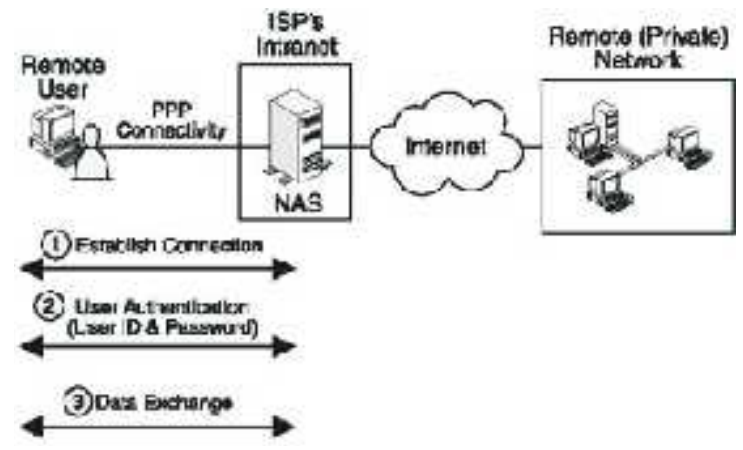

Gambar 5.Tiga Tanggung Jawab PPP dalam Transaksi PPTP 
(Dikutip dari: Gupta, M. (2003). Building a Virtual Private Network, Part II Chapter 5.

Ohio: Premier Press.)

"Secara arsitektur, PPTP membagi fungsi Remote Access Server (RAS) antara PPTP access concentrator (PAC) dimana remote user melakukan 'dial' ke dalamnya, dan PPTPNetwork Server (PNS) yang mengakhiri sesi PPP pada remote client, menyediakan akes ke jaringan perusahaan dan berperan sebagai server untuk satu PAC atau lebih." (Snader, 2005).

Setelah koneksi PPTP pada client dan server terbentuk, PPTP menggunakan beberapa pesan untuk mengendalikan koneksi. Pesan tersebut digunakan untuk merawat (maintenance), memanajemen dan mengakhiri tunnel PPTP. Karena PPTP dibentuk berdasarkan alamat IP, baik di sisi client maupun server, maka secara otomatis TCP port nomor 1723 akan dialokasikan dan dipesan pada masing-masing sisi.

\begin{tabular}{|c|l|l|c|c|}
\hline $\begin{array}{c}\text { Data- } \\
\text { Link } \\
\text { Header }\end{array}$ & Ir & TCr & $\begin{array}{c}\text { potp } \\
\text { Control } \\
\text { Messaje }\end{array}$ & $\begin{array}{l}\text { Calc- } \\
\text { Link } \\
\text { Trailer }\end{array}$ \\
\hline
\end{tabular}

Gambar 6.Paket Pengendali Koneksi PPTP

(Dikutip dari: http://technet.microsoft.com/en-us/library/cc779919(v=ws.10).aspx pada tanggal 22 September 2012.)

Pada gambar di atas (Gambar 6.), Snader (2005) menjelaskan bahwa panjangfield adalah panjang keseluruhan dari sebuah pesan PPTP, termasuk header.PPTP message type selalu diatur ke 1.Pesan ini menunjukkan pesan pengendali.Sedangkan magic cookie, selalu memiliki nilai $0 \mathrm{x} 1 \mathrm{a} 2 \mathrm{~b} 3 \mathrm{c} 4 \mathrm{~d}$. Hal ini digunakan untuk melakukan sinkronisasi dengan data stream TCP. Jika pesan berikutnya tidak memiliki nilai tersebut, maka penerima akan mengetahui bahwa penerima telah kehilangan sinkronisasi.

Tabel 1.

Pesan Pengendali PPTP (PPTP Control Message)

(Dikutip dari: Snader, Jon. C. (2005).VPNs Illustrated: Tunnels, VPNs, and IPsec, Chapter4 Section 4.5. New Jersey: Addison Wesley Professional.)

\begin{tabular}{|r|l|}
\hline \multicolumn{1}{|c|}{ Kode } & \multicolumn{1}{|c|}{ Pesan } \\
\hline \multicolumn{3}{|c|}{ Connection Control Management } \\
\hline 1 & Start-Control-Conection-Request \\
\hline 2 & Start-Control-Conection-Reply \\
\hline 3 & Start-Control-Conection-Request \\
\hline 4 & Start-Control-Conection-Reply \\
\hline 5 & Echo-Request \\
\hline 6 & Echo-Reply \\
\hline \multicolumn{2}{|c|}{ Call Management } \\
\hline 7 & Outgoing-Call-Request \\
\hline 8 & Outgoing-Call-Reply \\
\hline 9 & Incoming-Call-Request \\
\hline 10 & Incoming-Call-Reply \\
\hline 11 & Incoming-Call-Connected \\
\hline 12 & Call-Clear-Request \\
\hline 13 & Call-Disconnect-Notify \\
\hline \multicolumn{2}{|c|}{ Error Reporting } \\
\hline 14 & WAN-Error-Notify \\
\hline \multicolumn{3}{|c|}{ PPP Session Control } \\
\hline 15 & Set-Link Info \\
\hline
\end{tabular}


Tabel di atas adalah sebagian tipe dan format perintah dari perintah pengendali yang digunakan pada saat tunnel PPTP terbentuk.

\subsection{Ethernet over Internet Protocol (EoIP)}

Ethernet over Internet Protocol (EoIP) adalah protokol yang dikembangkan oleh MikroTik yang membuat sebuah Ethernet tunnel antara dua router dengan menggunakan koneksi IP.Interface EOIP terlihat sebagai interface Ethernet biasa (secara logikal). Ketika fungsi bridging diaktifkan, semua data yang ditransmisikan melalui Ethernet protocol pada kedua routerakan dijembatani (bridge) seolah-olah kedua router dihubungkan dengan kabel. Protokol ini dapat berjalan di atas PPTP tunnel dan IPIP tunnel atau yang lain yang berjalan di atas koneksi IP.

EoIP menggunakan protokol GRE untuk mengenkapsulasi data agar terbentuk sebuah EoIP Tunnel. Urutan enkapsulasi pada protokol EoIP adalah sebagai berikut: Internet Protocol (IP) pada Layer 3 akan dienkapsulasi dengan menggunakan teknologi Ethernet II pada Layer 2. Hasil enkapsulasi tersebut kemudian mengenkapsulasi protokol Generic Routing Encapsulation (GRE).Dengan cara inilah proses pembentukan EoIP tunnel terjadi dan digunakan untukmengirim dan menerima data. (Pramudya, 2009).EoIP bekerja menggunakan Tunnel ID yang harus bernilai sama antara kedua router yang memiliki EoIP interface dalam membentuk sebuah EoIP Tunnel. (Cahyadi, 2010). "EoIPinterface terlihat sebagai sebuah interface Ethernet." (MikroTik, 2004). Dalam pengimplementasiannya, EoIP Tunnel membutuhkan satu buah IP Public pada kedua router yang akan dihubungkan.

\section{Hasil dan Pembahasan}

3.1. Hardware

- Router MikroTik-PC x86

Router ini digunakan di PPUKDW. Spesifikasi router MikroTikPC x86 adalah sebagai berikut:

$\begin{array}{ll}\text { CPU } & : \text { Pentium } 731 \mathrm{MHz} \\ \text { MainStorage } & : 246.9 \mathrm{MB} \\ \text { RAM } & : 179.4 \mathrm{MB} \\ \text { LAN port } & : 7 \\ \text { Versi RouterOS } & : 4.3 \\ \text { License } & : \text { Level } 4\end{array}$

- Router MikroTik RB192

Router ini digunakan di SMA Budya Wacana. Spesifikasi router MikroTikRB192 adalah sebagai berikut:

CPU : MIPS 4Kc V0.11

Main Storage : $61.4 \mathrm{MB}$

RAM : $29.4 \mathrm{MB}$

LAN port $\quad: 9$

Wireless port $: 2$

Versi RouterOS : 3.0

License : Level 4

\subsection{Bandwidth dan IP Publik}

- PPUKDW

IP Publik : : 222.124.22.30

Upload : $2048 \mathrm{Kbps}$

Download : $512 \mathrm{Kbps}$

- SMA Budya Wacana

IP Publik : : 110.136 .160 .106

Upload : $64 \mathrm{Kbps}$

Download : : 1024 Kbps 


\subsection{Rancangan Topologi Penelitian}

Penelitian akan dimplementasikan pada topologi riil menggunakan jaringan Internet. Rancangan topologi yang akan digunakan dalam penelitian ini adalah sebagai berikut:

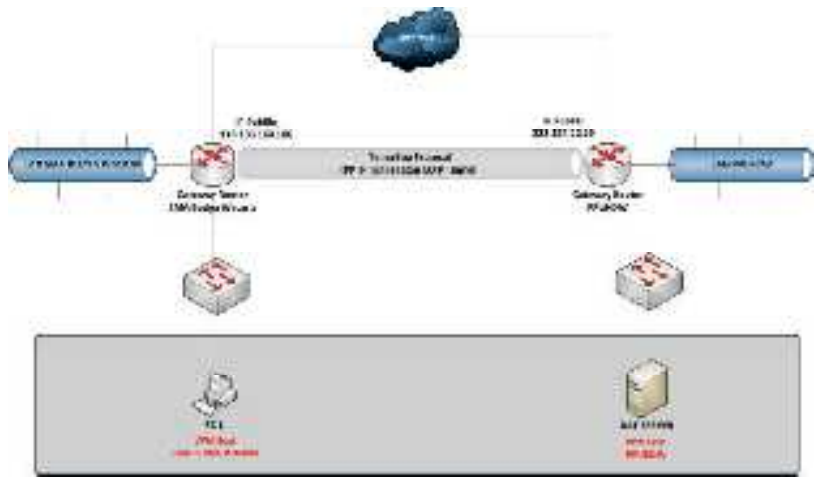

Gambar 7. Topologi Penelitian

Implementasi akan dilakukan pada dua tempat, PPUKDW dan SMA Budya Wacana dengan 2 (dua) buah router sesuai dengan spesifikasi yang terdapat pada subbab 3.1. dan 1 (satu) unit komputer client serta 1 (satu) unit komputer server sesuai dengan topologi di atas.Pengalamatan IP yang akan dikonfigurasi pada interface router dan komputer untuk penelitian sesuai dengan topologi tersebut seperti pada Tabel 2.

Tabel 2.

Pengalamatan IP

\begin{tabular}{|c|c|}
\hline Unit & Alamat IP \\
\hline Gateway Router PPUKDW (IP Publik) & 222.124 .22 .30 \\
\hline Gateway Router SMA Budya Wacana (IP Publik) & 110.136 .160 .106 \\
\hline Gateway Router PPUKDW (IP PPTP Tunneling) & $10.10 .100 .1 / 24$ \\
\hline Gateway Router SMA Budya Wacana (IP PPTP Tunneling) & $10.10 .100 .2 / 24$ \\
\hline Gateway Router PPUKDW (IP EOIP Tunneling) & $10.10 .200 .1 / 30$ \\
\hline Gateway Router SMA Budya Wacana (IP EOIP Tunneling) & $10.10 .200 .2 / 30$ \\
\hline DAT Server (VPN Host PPUKDW) & $172.17 .1 .200 / 24$ \\
\hline PC 1 (VPN Host SMA Budya Wacana) & $192.168 .103 .5 / 24$ \\
\hline
\end{tabular}

\subsection{Skema Pengujian}

Pengujian dilakukan untuk menguji performa berdasarkan throughput, packet loss dan delay. Pengujian dilakukan dengan mengambil sampel dari setiap skenario tersebut.

Pengujian direncanakan dilakukan selama 6 (enam) hari, dengan menjalankan aplikasi yang telah disediakan Microsoft Certified Desktop Aplication Training. Penelitian dilakukan mulai pukul 08.00 - 16.00 dengan interval waktu 1 (satu) jam. Setiap interval, dilakukan satu kali pengambilan untuk sampel data selama 10 (sepuluh) menit untuk satu protokol. Sampel data yang diambil berupa throughput, delay dan packet loss. Desain ini berlaku untuk kedua protokol, dan dilakukan secara bergantian, yang akan dijelaskan melalui tabel di bawah ini (Tabel 3.)

Tabel 3.

Waktu Perencanaan Pengujian

\begin{tabular}{|c|c|c|c|}
\hline Hari, Tanggal & Waktu & Lama Pengujian & Protokol yang Diuji \\
\hline \multirow{4}{*}{$\begin{array}{c}\text { Senin-Sabtu, } \\
\text { 22-27 Oktober 2012 }\end{array}$} & $08.00-09.00$ & 10 menit & EoIP \\
\cline { 2 - 4 } & $09.00-10.00$ & 10 menit & PPTP \\
\cline { 2 - 4 } & \multirow{2}{*}{$10.00-11.00$} & 10 menit & EoIP \\
\cline { 3 - 4 } & & 10 menit & PPTP \\
\hline
\end{tabular}


Tabel 3. ( Lanjutan )

Waktu Perencanaan Pengujian

\begin{tabular}{|l|c|c|c|}
\hline \multirow{4}{*}{$11.00-12.00$} & 10 menit & EoIP \\
\cline { 2 - 4 } & \multirow{2}{*}{$12.00-13.00$} & 10 menit & PPTP \\
\cline { 2 - 4 } & & 10 menit & EoIP \\
\cline { 2 - 4 } & \multirow{2}{*}{$13.00-14.00$} & 10 menit & PPTP \\
\cline { 2 - 4 } & & 10 menit & EoIP \\
\cline { 2 - 4 } & \multirow{2}{*}{$14.00-15.00$} & 10 menit & PPTP \\
\cline { 2 - 4 } & \multirow{2}{*}{$15.00-16.00$} & 10 menit & PoIP \\
\cline { 3 - 4 } & & 10 menit & EoIP \\
\hline
\end{tabular}

\subsubsection{PengujianThroughput}

Pengujian throughput dilakukan sebanyak satu kali dalam satu interval waktu (satu sesi). Pengambilan data dilakukan setiap detik selama 10 (sepuluh) menit pada trafik TCP.

Tabel 4.

Skema Pengujian Throughput

\begin{tabular}{|c|c|c|c|}
\hline Sesi & Lama Pengambilan Data & EoIP & PPTP \\
\hline $08.00-09.00$ & 10 Menit & TCP & TCP \\
\hline $09.00-10.00$ & 10 Menit & TCP & TCP \\
\hline $10.00-11.00$ & 10 Menit & TCP & TCP \\
\hline $11.00-12.00$ & 10 Menit & TCP & TCP \\
\hline $12.00-13.00$ & 10 Menit & TCP & TCP \\
\hline $13.00-14.00$ & 10 Menit & TCP & TCP \\
\hline $14.00-15.00$ & 10 Menit & TCP & TCP \\
\hline $15.00-16.00$ & 10 Menit & TCP & \\
\hline
\end{tabular}

Pengujian throughput dilakukan dengan mengirimkan trafik TCP menggunakan JPerf. Aplikasi ini mampu mengirimkan trafik TCP atau UDP serta melakukan pengukuran throughput untuk melakukan monitoring jaringan. Karena aplikasi ini bersifat client-server, maka pada penelitian ini, DAT Server sesuai dengan topologi di atas akan bertindak sebagai server side, sedangkan PC1 akan bertindak sebagai client side.

\subsubsection{Pengujian Delay}

Pengujian delay dilakukan dengan cara sniffing packet menggunakan aplikasi Wireshark. Seperti pengujian throughput, sniffing dilakukan pada paket TCP selama 10 (sepuluh) menit. File hasil capture packet selama sniffing kemudian diolah menggunakan aplikasi Microsoft Excel untuk mendapatkan rata-rata delay selama satu sesi.

\subsubsection{Pengujian Packet Loss}

Pengujian packet loss dilakukan dengan menggunakan aplikasi Wireshark. Paket TCP karena bersifat connection oriented yang memiliki mekanisme pengiriman ulang paket (packet retransmission) apabila terdapat kegagalan atau hilang sampai tujuan, sehingga paket yang gagal atau hilang dapat dilakukan pengujian untuk dihitung. Pada Wireshark, paket yang dikirim ulang akan diberi warna hitam. Packet loss dihitung berdasarkan jumlah paket yang gagal dikirimkan dibagi dengan total paket dikalikan dengan 100\% (packet loss ditampilkan berdasarkan persentase). Pada Wireshark, packet loss dapat dihitung dengan membagi paket yang displayed dengan total packet.

\subsection{Analisis Hasil Pengujian}

Analisis hasil pengujian yang telah dilakukan selama 6 (enam) hari diselesaikan menggunakan metode pengujian statistik. Metode tersebut digunakan untuk membantu menemukan kesimpulan yang didapat secara matematis dari hasil pengolahan data yang ada. 
Pengujian statistik dilakukan untuk membandingkan performa Protokol EoIP dan PPTP menggunakan 3(tiga) parameter yang didapatkan, yaitu rata-rata throughput, packet loss, dan delay, baik pada sisi server maupun client setiap harinya, serta membandingkan performa kedua protokol tersebut selama 6 (enam) hari. Dengan demikian, diharapkan hasil dari penggunaan metode pengujian statistik ini dapat membantu membuat kesimpulan dari perbandingan performa kedua protokol tersebut dan dapat melengkapi kesimpulan yang dari penelitian yang telah dilakukan.

Perbandingan hasil pengujian throughput dilakukan dengan dugaan bahwa Protokol PPTP memiliki throughput yang lebih besar dari Protokol EoIP. Dugaan tersebut nantinya akan menjadi $H_{l}$ dan kebalikan dari dugaan tersebut akan menjadi $H_{0}$. Untuk perbandingan hasil pengujian packet loss, dilakukan dengan dugaan bahwa Protokol PPTP memiliki packet loss yang lebih kecil dari Protokol EoIP. Dugaan tersebut nantinya akan menjadi $H_{1}$ dan kebalikan dari dugaan tesebut akan menjadi $H_{0}$. Sedangkan perbandingan hasil pengujian delay dilakukan dengan dugaan bahwa Protokol PPTP memiliki delay yang lebih kecil dari Protokol EoIP. Dugaan tersebut nantinya akan menjadi $H_{l}$ dan kebalikan dari dugaan tesebut akan menjadi $H_{0}$.

Berikut ini adalah analisis hasil pengujian throughput yang dilakukan pada hari Senin, 22 Oktober 2012 menggunakan metode pengujian statistik Distribusi T (T-Test):

Tabel 5.

Data Pengujian Throughput pada Hari Senin, 22 Oktober 2012

\begin{tabular}{|r|c|r|r|r|}
\hline Pengujian ke- & Waktu (Pukul) & Protokol EoIP & \multicolumn{1}{c|}{ Protokol PPTP } & \multicolumn{1}{c|}{ Selisih } \\
\hline 1 & $08.00-09.00$ & 0.09 & 0.12 & -0.03 \\
\hline 2 & $09.00-10.00$ & 0.14 & 0.12 & 0.02 \\
\hline 3 & $10.00-11.00$ & 0.14 & 0.13 & 0.01 \\
\hline 4 & $11.00-12.00$ & 0.02 & 0.04 & -0.02 \\
\hline 5 & $12.00-13.00$ & 0.18 & 0.17 & 0.01 \\
\hline 6 & $13.00-14.00$ & 0.16 & 0.00 & 0.16 \\
\hline 7 & $14.00-15.00$ & 0.02 & 0.07 & -0.05 \\
\hline 8 & $15.00-16.00$ & 0.16 & 0.09 & 0.07 \\
\hline
\end{tabular}

Langkah uji statistiknya adalah:

1. Menentukan hipotesis:

$$
H_{0}: \mu_{E O I P}-\mu_{P P T P} \geq 0 \text { vs } H_{1}: \mu_{E o I P}-\mu_{P P T P}<0
$$

Dengan:

$H_{0}$ : Pada hari Senin, baik di sisi server maupun client, rata-rata throughput pada Protokol EoIP lebih besar dari atau sama dengan rata-rata throughput pada Protokol PPTP.

$H_{1}$ : Pada hari Senin, baik di sisi server maupun client, rata-rata throughput pada Protokol EoIP lebih kecil dari rata-rata throughput pada Protokol PPTP.

2. Statistik uji:

$$
t_{h}=\frac{\bar{x}_{D}-0}{S_{D} / \sqrt{n_{D}}}
$$

3. Tingkat signifikansi $\alpha=0,05$; sehingga $n_{D}-1=7$ dan $t_{(7 ; 0,05)}=1,895$ (nilai tersebut berasal dari Tabel Distribusi t). $n_{D}$ adalah jumlah pengujian yang dilakukan. Dalam penelitian ini nilai $n_{D}=8$.

4. Daerah Penolakan $H_{0}$ :

5. Hitungan: $H_{0}$ ditolak bila $t_{h}<-1,895$

$$
\begin{gathered}
\bar{x}_{D}=0,021250 ; s_{D}=0,066855 ; \sqrt{n_{D}}=\sqrt{8}=2,828427, \text { sehingga } \\
t_{h}=\frac{0,021250}{0,066855 / 2,828427}=0,899016
\end{gathered}
$$


6. Kesimpulan:

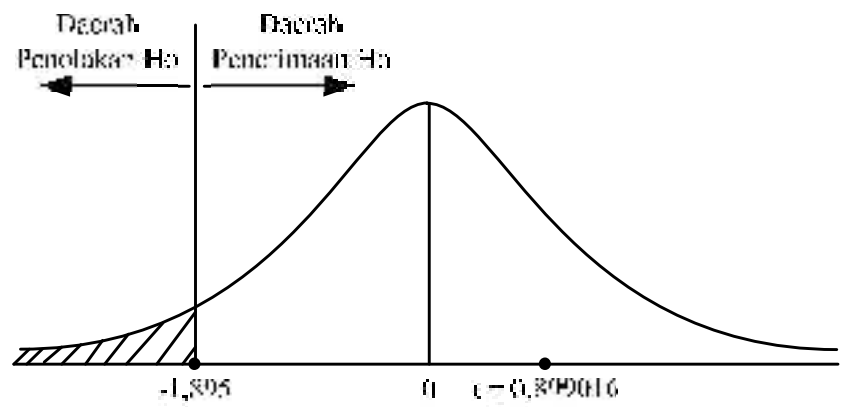

Gambar 8. Grafik Distribusi t Perbandingan Throughput

$H_{0}$ diterima karena nilai t tidak berada pada daerah penolakan $H_{0}$. Hal ini berarti pernyataan yang menyatakan bahwa pada hari Senin, baik di sisi server maupun client, rata-rata throughput pada Protokol EoIP lebih besar dari atau sama dengan rata-rata throughput pada Protokol PPTP dapat diterima. Dengan kata lain, pada hari Senin, baik di sisi server maupun client, rata-rata throughput pada Protokol EoIP lebih baik daripada rata-rata throughput pada Protokol PPTP pada tingkat signifikansi 5\%.

Perhitungan menggunakan metode pengujian statistik di atas dilakukan untuk semua hasil pengujian (throughput, packet loss, dan delay), baik pada sisi server maupun pada sisi client. Dari perhitungan tersebut, didapatkan hasil seperti yang dijelaskan pada subbab berikutnya.

\subsubsection{Analisis Throughput}

Salah satu parameter yang mempengaruhi performaadalah besar kecilnya throughput yang dihasilkan. Semakin besar throughput, maka semakin baik performa dari jaringan tersebut, begitu pula sebaliknya. Berikut ini hasil analisis setelah dilakukan perhitungan.

\section{- Analisis per Hari}

Tabel 6.

Analisis Perbandingan Throughput per Hari

\begin{tabular}{|l|c|c|}
\hline \multirow{2}{*}{\multicolumn{1}{|c|}{ Hari, Tanggal }} & \multicolumn{2}{c|}{ Server/ Client } \\
\cline { 2 - 3 } & EoIP & PPTP \\
\hline Senin, 22 Oktober 2012 & lebih baik & - \\
\hline Selasa, 23 Oktober 2012 & lebih baik & - \\
\hline Rabu, 24 Oktober 2012 & lebih baik & - \\
\hline Kamis, 25 Oktober 2012 & lebih baik & - \\
\hline Jum'at, 26 Oktober 2012 & lebih baik & - \\
\hline Sabtu, 27 Oktober 2012 & lebih baik & - \\
\hline
\end{tabular}

\section{- Analisis selama 6 (Enam) Hari}

Tabel 7.

Analisis Perbandingan Throughput selama 6 (Enam) Hari

\begin{tabular}{|l|c|c|}
\hline \multirow{2}{*}{ Lama Penelitian } & \multicolumn{2}{|c|}{ Server/Client } \\
\cline { 2 - 3 } & EoIP & PPTP \\
\hline 6 (enam) hari & lebih baik & - \\
\hline
\end{tabular}

Dari penelitian dan perhitungan menggunakan metode pengujian statistik terhadap throughput, baik di sisi server maupun client dapat disimpulkan bahwa:

- Protokol EoIP memiliki rata-rata throughput yang lebih baik daripada Protokol PPTP setiap harinya. 
- Dalam kurun waktu 6 (enam) hari, kecendurungan rata-rata throughput pada Protokol EoIP lebih baik daripada Protokol PPTP.

- Dalam kurun waktu 6 (enam) hari, kecendurungan rata-rata throughput menunjukkan bahwa rata-rata throughput yang dihasilkan oleh Protokol EoIP lebih besar dari rata-rata throughput yang dihasilkan oleh Protokol PPTP.

\subsubsection{Analisis Packet Loss}

Parameter kedua yang mempengaruhi performaadalah besar kecilnya packet loss.Packet loss dengan prosentase yang besar mengakibatkan bandwidth yang dibutuhkan pada sebuah jaringan menjadi lebih besar karena paket yang hilang harus dikirim berulangulang hingga paket tersebut sampai pada tujuan. Dengan demikian, semakin kecil prosentasi packet loss, semakin baik performa jaringan. Berikut ini hasil analisis setelah dilakukan perhitungan.

\section{- Analisis per Hari}

Tabel 8.

Analisis Perbandingan Packet Loss per Hari

\begin{tabular}{|l|c|c|c|c|}
\hline \multirow{2}{*}{ Hari, Tanggal } & \multicolumn{2}{c|}{ Server } & \multicolumn{2}{c|}{ Client } \\
\cline { 2 - 5 } & EoIP & PPTP & EoIP & PPTP \\
\hline Senin, 22 Oktober 2012 & lebih baik & - & lebih baik & - \\
\hline Selasa, 23 Oktober 2012 & lebih baik & - & lebih baik & - \\
\hline Rabu, 24 Oktober 2012 & lebih baik & - & lebih baik & - \\
\hline Kamis, 25 Oktober 2012 & lebih baik & - & lebih baik & - \\
\hline Jum'at, 26 Oktober 2012 & & lebih baik & - & lebih baik \\
\hline Sabtu, 27 Oktober 2012 & lebih baik & - & - & lebih baik \\
\hline
\end{tabular}

\section{- Analisis selama 6 (Enam) Hari}

Tabel 9.

Analisis Perbandingan Packet Loss selama 6 (Enam) Hari

\begin{tabular}{|l|c|c|c|c|}
\hline \multirow{2}{*}{ Lama Penelitian } & \multicolumn{2}{|c|}{ Server } & \multicolumn{2}{c|}{ Client } \\
\cline { 2 - 5 } & EoIP & PPTP & EoIP & PPTP \\
\hline 6 (enam) hari & - & lebih baik & - & lebih baik \\
\hline
\end{tabular}

Dari penelitian dan perhitungan menggunakan metode pengujian statistik terhadap packet loss, baik di sisi server maupun client dapat disimpulkan bahwa:

- Pada sisi server, rata-rata packet loss pada Protokol EoIP yang lebih baik daripada Protokol PPTP terdapat pada hari Senin-Kamis dan Sabtu. Sedangkan pada hari Jum'at, rata-rata packet loss pada Protokol PPTP lebih baik daripada Protokol EoIP.

- Pada sisi client, rata-rata packet loss pada Protokol EoIP yang lebih baik daripada Protokol PPTP terdapat pada hari Senin-Kamis. Sedangkan pada hari Jum'at dan Sabtu, rata-rata packet loss pada Protokol PPTP lebih baik daripada Protokol EoIP.

- Dalam kurun waktu 6 (enam) hari, kecendurungan rata-rata packet loss pada Protokol PPTP lebih baik daripada Protokol EoIP.

\subsubsection{Analisis Delay}

Parameter ketiga yang mempengaruhi performaadalah besar kecilnya delay. Berikut ini hasil analisis dari kesimpulan yang didapatkan dari perhitungan pada Subbab 4.6.2 dan 4.6.3. 


\section{- Analisis per Hari}

Tabel 10.

Analisis Perbandingan Delay per Hari

\begin{tabular}{|l|c|c|c|c|}
\hline \multirow{2}{*}{ Hari, Tanggal } & \multicolumn{2}{c|}{ Server } & \multicolumn{2}{c|}{ Client } \\
\cline { 2 - 5 } & EoIP & PPTP & EoIP & PPTP \\
\hline Senin, 22 Oktober 2012 & lebih baik & - & lebih baik & - \\
\hline Selasa, 23 Oktober 2012 & lebih baik & - & lebih baik & - \\
\hline Rabu, 24 Oktober 2012 & lebih baik & - & lebih baik & - \\
\hline Kamis, 25 Oktober 2012 & lebih baik & - & lebih baik & - \\
\hline Jum'at, 26 Oktober 2012 & lebih baik & - & - & lebih baik \\
\hline Sabtu, 27 Oktober 2012 & lebih baik & - & lebih baik & - \\
\hline
\end{tabular}

\section{- Analisis selama 6 (Enam) Hari}

Tabel 11.

Analisis Perbandingan Delay selama 6 (Enam) Hari

\begin{tabular}{|l|c|c|c|c|}
\hline \multirow{2}{*}{ Lama Penelitian } & \multicolumn{2}{|c|}{ Server } & \multicolumn{2}{c|}{ Client } \\
\cline { 2 - 5 } & EoIP & PPTP & EoIP & PPTP \\
\hline 6 (enam) hari & lebih baik & - & lebih baik & - \\
\hline
\end{tabular}

Dari penelitian dan perhitungan menggunakan metode pengujian statistik terhadap delay, baik di sisi server maupun client dapat disimpulkan bahwa:

- Pada sisi server, rata-rata delay pada Protokol EoIP lebih baik daripada Protokol PPTP setiap harinya.

- Pada sisi client, rata-rata delay pada Protokol EoIP yang lebih baik daripada Protokol PPTP terdapat pada hari Senin-Kamis dan Sabtu. Sedangkan pada hari Sabtu, rata-rata delay pada Protokol PPTP lebih baik daripada Protokol EoIP.

- Dalam kurun waktu 6 (enam) hari, kecendurungan rata-rata delay pada Protokol EoIP lebih baik daripada Protokol PPTP.

\section{Kesimpulan}

Berdasarkan hasil penelitian yang telah diuraikan pada Bab 4, diperoleh beberapa kesimpulan, yaitu:

a. Dalam keseharian, baik dari sisi server maupun sisi client, Protokol EoIP memiliki performa yang lebih baik daripada Protokol PPTP karena Protokol EoIP memiliki rata-rata throughput yang lebih besar dari Protokol PPTP serta rata-rata packet loss dan delay yang lebih kecil dari Protokol PPTP.

b. Dalam kurun waktu 6 (enam) hari, baik dari sisi server maupun sisi client, Protokol EoIP memiliki kecenderungan (trend) performa yang lebih baik daripada Protokol PPTP dalam hal rata-rata throughput dan delay. Sedangkan dalam hal rata-rata packet loss, rata-rata packet loss pada Protokol PPTP lebih baik daripada Protokol EoIP.

c. Dalam keadaan pada topologi riil, performa yang paling baik dan optimal, dapat dilakukan pada hari Jum'at dan Sabtu karena pada kedua hari ini rata-rata throughput, packet loss dan delay lebih kecil dibanding hari Senin-Kamis.

d. Dari hasil implementasi dan pengujian yang diterapkan pada topologi riil, diamati bahwa pembentukan VPN menggunakan kedua protokol yang diimplementasi dan diuji dipengaruhi oleh trafik atau lalu lintas data pada jaringan lokal di masingmasing titik.

\section{Penutup}

Demikianlah penelitian dan analisis perbandingan performa yang dilakukan terhadap implementasi Point-to-Point Tunneling Protocol (PPTP) dan Ethernet over 
Internet Protocol (EoIP) berdasarkan 3 (tiga) parameter, yaitu throughput, packet loss dan delay. Semoga penelitian ini dapat memberi pertimbangan dalam pemilihan protokol yang akan diterapkan pada sebuahVPN sehingga protokol yang digunakan dan diterapkan dapat membentuk sebuah VPN dengan performa yang lebih optimal.

\section{Daftar Pustaka}

Cahyadi, D. (2010). Pemanfaatan Fitur Tunneling Menggunakan Virtual Interface EoIP di MikrotikRouterOS Untuk Koneksi Bridging Antar Kantor Melalui Jaringan ADSL Telkom Speedy. Jurnal Informatika Mulawarman. Samarinda: Universitas Mulawarman, 5(2), 50 - 54. Diakses pada tanggal 10 September 2012 dari http://informatikamulawarman.files.word press.com/2011/10/01-jurnal-informatikamulawarman-feb-2011.pdf

Feilner, M. (2006). OpenVPN: Building and Integrating Virtual Private Network. Birmingham: Packt Publishing.

Gupta, M. (2003). Building a Virtual Private Network. Ohio: Premier Press.

Lewis, M. (2006). Comparing, Designing, and Deploying VPNs. Indianapolis: Cisco Press.

Luo, W., Pignataro, C., Bokotey, D. \& Chan, A. (2005). Layer 2 VPN Architectures. Indianapolis: Cisco Press.

Microsoft. (2012). Understanding PPTP (Windows NT 4.0). Diakses pada tanggal 12 September 2012 dari http://technet.microsoft.com/en-us/library/cc768084.aspx

Mikrotik. (2004). Manual: Interface/EoIP. Diakses pada tanggal 10 September 2012 dari http://wiki.mikrotik.com/wiki/Manual:Interface/EoIP

. (2008). PPTP. Diakses pada tanggal 10 September 2012 dari http://www.mikrotik.com/testdocs/ros/2.9/interface/pptp.php

Pramudya, N. (2009). Implementasi Dan Analisis Point-To-Point Tunneling Protocol Serta Ethernet Over Internet Protocol Sebagai Metode Untuk Membuat Virtual Private Network. Diakses pada tanggal 5 September 2012 dari http://sinta.ukdw.ac.id/sinta/search.jsp?query=pptp\&btnsearch= Cari

Santosa, G. R. (2004). Statistik. Yogyakarta: Penerbit Andi.

Scott, C., Wolfe, P., \& Erwin M. (1999). Virtual Private Network, Second Edition. California: O'Reilly.

Snader, J.C. (2005). VPN Illustrated: Tunnels, VPNs, and IPsec. New Jersey, Addison Wesley Professional.

Vachon, B., \& Graziani, R. (2008). Accessing the WAN-CCNA Exploration Companion Guide. Indianapolis: Cisco Press. 
